\title{
The Asymmetric Effect of Sex Role Orientation on Japanese Family Purchase Decision Making
}

Zsolt Varga, Wirawan Dony Dahana*, and Sotaro Katsumata

Graduate School of Economics, Osaka University, Osaka, Japan

\begin{abstract}
Family purchase decision making is driven by the bipolar gender stereotypes of husband and wife. However relatively little is known about how individual perceptions of Sex Role Orientation (SRO) affect authority in an integrated decision. The present research is aimed to narrow the gap in the literature by dissecting the four dimensions of Sex Role Orientation and exploring the interplay among the elements of household decision making: SRO, gender, and purchase decision stage. The authors carry out a comprehensive analysis by utilizing representative empirical data collected from 500 demographically heterogeneous individuals who filled out a survey related to gender role orientation and automobile purchasing behavior. The analysis reveals asymmetric effects of females and males norm perceptions. While the fundamental relationship between SRO and decision making authority is predominated solely by the gravity of male values, the moderating effect of gender is primarily affected by female dimensions. The research breaks beyond the limitations of prior research by elucidating households' decision making structure through isolating the dimensions of female and male gender norms, and contributes to the literature by providing a deeper and more comprehensive insight into the underlying factors of decision making mechanism between husband and wife. In addition, given the sparse research on gender roles and purchasing behavior in Japanese society, the results provide a basis for cross-cultural comparison and actionable items for immediate management implication by practitioners.
\end{abstract}

Keywords: Sex role orientation; Family purchase decision; Consumer behavior; Gender

\section{Introduction}

The influence of Sex Role Orientation (SRO) on household decision making is well acknowledged, although within a family, husband and wife often have incongruent perceptions. What is the effect of the polarity of female and male individual perceptions of authority in an integrated decision? In case of extensive buying problems, such as consumer durable purchases, these often incompatible perceptions have to merge into one consolidated mechanism [1]. The crucial factor determining authority is gender role orientation [2,3]; a transgenerational cultural imprint built on norms prescribing roles and inequalities specifically between men and women $[4,5]$. The importance of the issue has been pointed out by a large number of studies [5-10]. However, the theory of family decision making still heavily relies on the conceptual developments of studies published in the 1960s and 1970s [1].

Conversion into modern society rearranged the gender stereotypes [11]. Wives' influence increased over all decision areas [4], opening a new, fertile area for research. Few authors have attempted to measure the profound alterations occurring in family decision making within the modern family, despite 'frantic' changes in the family structure $[4,5]$.

In a general sense, a person's Sex Role Orientation can be measured on a uni-dimensional modern-traditional scale; however, in order to better understand its intricate relationship with decision making mechanism, the framework seems to be inadequate. Scanzoni [12] dissected SRO into four underlying dimensions: traditional wife (TW), the wife's self-actualization (SA), traditional husband (TH) and husband alteration (HA). Despite the conclusion that each element should be examined separately, the majority of later studies continue to measure the absolute score of spouses. The individual effects of SRO dimensions on decision authority might provide further theoretical development [5] and an untapped source of practical insight.
Over the past decades, SRO and its effect on purchase decision making has been investigated in several Western countries. By contrast, how the construct affects Japanese marital consumer decision making remains underexplored. Part of the reasons is that the majority of previous studies focused solely on Western societies [13], forsaking the observation of Japanese cultural differences, despite gender role development evolved in a significantly different way [11]. Thus, an exploratory investigation of Japanese married couples' purchasing dyad and cross cultural comparison should be a great concern for global marketers and researchers.

\section{Research objectives}

The objective of the present research is twofold. First, it is intended to fill the gap in the literature and further develop the extant theoretical framework by exploring the interplay between individual genderspecific SRO dimensions and decision making authority. And second, to explore Japanese household decision making and provide adequate material for cross-cultural comparison with Western cultures. Nevertheless, the strategic purpose of the study is not only to delineate the actual state of progress, but also to elicit relevant findings that might be useful for future research.

\section{Literature Review}

Literature regarding family decision making is extensive as the topic has been approached from multidisciplinary perspectives, both

*Corresponding author: Wirawan Dony Dahana, Graduate School of Economics, Osaka University, Osaka, Japan, Tel: +81-668505241; E-mail: dony@econ.osaka-u.ac.jp Received April 05, 2018; Accepted April 12, 2018; Published April 19, 2018

Citation: Varga Z, Dahana WD, Katsumata S (2018) The Asymmetric Effect of Sex Role Orientation on Japanese Family Purchase Decision Making. J Account Mark 7: 266. doi: 10.4172/2168-9601.1000266

Copyright: ( 2018 Varga Z, et al. This is an open-access article distributed unde the terms of the Creative Commons Attribution License, which permits unrestricted use, distribution, and reproduction in any medium, provided the original author and source are credited. 
macro and micro [1]. Because our research focuses on the relationship between family decision making and Sex Role Orientation, in the subsequent section we will review some studies related to household influence that has contributed to the body of knowledge.

\section{Family purchase decision making}

As early as 1951, Strodtbeck [14] proposed that the relative role and influence of husband and wife should be investigated to understand the nature of family purchase decision making, opening a passage for subsequent research development [14-18]. The foundations of households' decision-making structure rely on the micro perspectives of social power theory [19] and resource theory [15], which provide the basic elements contributing to decision making power within the family. Davis and Rigaux [17] established a milestone by proposing the simplification of previous studies considering only the outcome phase and investigated marital role influence at each stage of the decision making process. Davis [20] concluded that the spouses' involvement varies across stages, families, and product categories. The role specialization was confirmed in a study by Bonfield [21]. Further, Putman and Davidson [22] found evidence for a shift towards greater reliance on joint decision making in case of "riskier" purchases. Scores of articles studied the decision making process of adults, however, since the 1990s less attention has been devoted to examining the roles of husband and wife [1], despite most authors suggest a rapid change in gender norms $[23,24]$, which eventually could have significant effects on buying behavior [2-3].

Children's influence in consumer decision making is evident; however, in case of consumer durables their impact appears to be limited [25], leaving the concern of decision making authority for the parents.

To understand the dynamics of authority, a number of mediating variables have been examined by researchers. Some of the most commonly cited and supported evident factors are: class and ethnic background [26], referent power [27], the stage of family life cycle [28], the role of social networks [29], marital satisfaction [30], possible conflict between spouses [5], expert power [31] and the role of egalitarianism [16,32].

\section{Sex Role Orientation}

The concept of Sex Role Orientation (SRO) and its influence over purchase decision making authority has gained ground since the 1970s, which is considered as one of the key factors determining household authority pertaining to all family behavior [3]. SRO is a combination of attitudes and behavioral patterns toward the responsibilities and duties of females and males, determining gender specific role allocation, altering the behavior and influencing the social power of husband and wife $[28,33]$. Sex role norms congruency between husband and wife enables a family to accomplish several tasks efficiently and avoid conflicts. Traditional households prescribe gender specific activities, such as placing decision making authority on the husband. In contrast, "modern" egalitarian perceptions promote joint task responsibility [33] and allow non-traditional sex role activities [34,35]. In other words, traditional values emphasize autocratic allocation of decision making power, authorizing the husband $[4,15]$, while modern values lead to a more equal division of power between spouses [36-38,32].

Several researchers attempted to measure gender role orientation and developed a wide range of techniques. The Bem Sex-Role Inventory (BSRI) [9] is a measure of gender roles and gender expressions based on masculinity and femininity values, which is used to assess how spouses identify themselves psychologically. It was designed to capture a person's sex role androgyny on the premise that all people exhibit femininity and masculinity regardless of their sex. Another widely used measurement technique is the Osmond and Martin Sex Role Attitude scale (OMSRA) [39], which provides a broader measurement of SRO, encompassing the assessment of an individual's attitudes toward gender roles in the household, work situations, lifestyles and personality traits. Sugihara and Katsurada [11] found differences on the cultural interpretations of the BSRI in case of Japanese society, and Qualls [4] concluded that both BSRI and OMSRA provide fairly limited insight into household decision making compared to the Scanzoni Sex Role Indicator (SSRI) [32]. The SSRI is not only highly validated, but extends the vertical framework by dividing SRO into two female dimensions (traditional wife: TW, wife self-actualization: SA) and two male dimensions (traditional husband: TH, husband alterations: HA), enabling the investigation of individual perceptions of gender-specific sex role norms separately.

\section{Japanese cultural considerations}

Cultural imprinting crucially affects the extent of joint decisions and spousal domination in purchase decisions [40]. In order to provide a comparative base of evaluation, we briefly summarize the development and characteristics of gender roles in Japan.

Although during feudal times gender expectations in Japan were not as distinct as they were in Western cultures, the adaption of NeoConfucianism has given rise to emphasis on the hierarchical societal structure which endorsed male dominance both in the home and in the workplace [41], resulting in the development of a strongly patriarchal society [42]. As Japan transformed into a modern technological country, the gender division of labor became apparent and ethics were adapted and transformed into work settings to achieve economic prosperity. As men became devoted to their work, women took control over the management of the family's budget, leading to an increase in wives' decision making power [11].

The modern Japan is one of the most masculine countries in the world [43], where differentiated sex roles are strongly emphasized [44]. Although the women's rights movement and feminist values are still in an early stage [15], the last two decades has witnessed the steadily rising number of women working outside their homes, delaying marriage and keeping their jobs after marriage (Statistics Bureau of Japan, 2018), indicating that families have started to explore and embrace alternative lifestyles [45]. Several authors underline that family structure in developed economies are changing dramatically; "new families" incorporating modern family structures and traditional ones operating under changed decision making circumstances [46,47].

Very few authors took on the challenge of cross-cultural comparison; Ford et al. [13] found that China is husband dominated society, with little wife role specialization or syncretic decision making is allowed as compared to that in the US. The authors further discovered that Japanese household decisions are still heavily male dominated.

\section{Conceptual Framework}

The proposed conceptual framework (Figure 1) comprises of six independent variables: Sex, decision making stage, and the four dimensions of SRO (TW, SA, TH, HA). The dependent variable is decision making authority, comprising the influencing power of spouses.

\section{Hypotheses development}

Several studies suggest that women are more sex-role modern than 


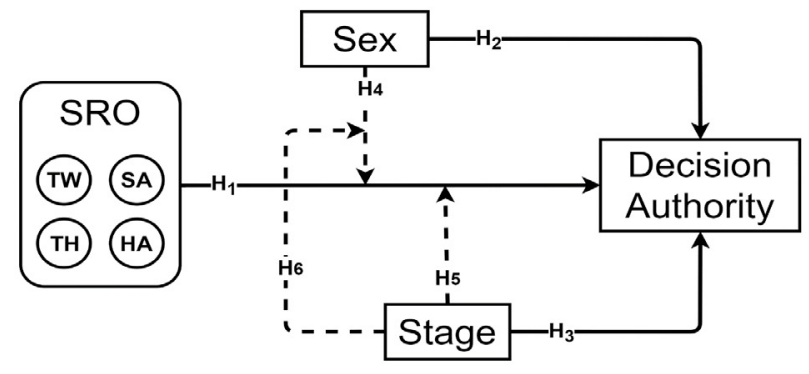

Figure 1: Conceptual framework.

men, and that the husband's influence correlates negatively with role modernity $[37,48]$. A higher level of egalitarianism results in more joint, more wife dominated and less husband dominated decisions $[2,13,32,36]$. Therefore, our first hypothesis is:

\section{$\mathrm{H}_{1}$ : $\mathrm{SRO}$ affects decision authority between husband and wife.}

In Japanese society, patriarchal norms and the dominant role of the husband are emphasized [49]. Furthermore, automobile product choices are traditionally husband-dominated $[1,3]$ through all stages of the purchase decision process, leading to the second hypothesis:

$\mathrm{H}_{2}$ : Husbands tend to exert higher levels of authority, while wives tend to be more subordinated.

Early studies have identified $[5,17,50]$ and a great number of publications provide reinforcing evidence [1] that marital power varies across decision stages. Our third hypothesis is:

\section{$\mathrm{H}_{3}$ : Authority level varies across decision stages.}

One of the main purposes of our study is to examine whether husbands' and wives' SRO have an asymmetric effect on determining decision making authority, therefore our proposed fourth hypothesis is:

\section{$\mathrm{H}_{4}$ : SRO's effect on authority is moderated by sex.}

According to the landmark study of Davis and Rigaux [17]; husbands' authority is more prevalent during the information search and evaluation of alternative stages and less dominant at the final decision stage. Likewise, Belch et al. [51] concluded that spouses' influence varies by decision stage. Accordingly, our fifth hypothesis is:

\section{$\mathrm{H}_{5}$ : SRO's effect on authority is moderated by the decision stage.}

The exploratory nature of the study compels us to test the holistic interrelationship between gender, decision stage and decision making authority, therefore, our sixth hypothesis is:

$\mathrm{H}_{6}$ : The moderating effect of gender on SRO varies depending on decision stages.

\section{Materials and Methodology}

A total of 500 married individuals; 250 men and 250 women participated in the study. The data was collected using the service provided by a survey company to ensure the heterogeneity and accurate representation of Japanese population. The survey's preconditions ensured that all respondents are married, have obtained a driving license and have purchased a car within the past 12 months.

The questionnaire consisted of $1+21+3$ questions. Respondents were asked about their demographic indicators (wife or husband), 21 SRO items, and the family decision making structure for each decision stage (information search, alternative evaluation, and final decision).
Decision authority is used as the dependent variable. Respondents answered a question related to the three classical purchase decision stages (information search, evaluation of alternatives and final decision) regarding their perceived authority during each stage of recently bought car purchase decision on a 1-5 Likert scale ( $1=\mathrm{I}$ completely did it, $5=$ My spouse completely did it).

Scanzoni's Sex Role Orientation scale (SSRO) [34] was used as an independent variable to measure the perceived gender role orientation of the respondents. The questionnaire has been validated and proven to be reliable by a number of authors $[5,37]$ and is the most widely used SRO measurement for studies related to family decision making. The scale was developed to allow the measurement of gender role orientation of either the husband or the wife separately. The questionnaire uses 21 Likert-scaled (1-5) batteries tapping four underlying dimensions: Traditional wife (TW) and self-actualization (SA) for women, and traditional husband (TH) and husband alterations (HA) for men. In case of TW and TH: higher scores indicate that the respondent's perceptions are based on traditional family values, while lower scores represent modern values. Further, high SA and HA scores are interpreted as modern values, while lower scores of the items correspond to traditional views.

As suggested by previous authors [52], data regarding the respondents' gender, personal income, family income, employment status, age, married years, living area, number of children and education has been collected.

\section{Results}

The profile of the sample population is representative for the entire Japanese population and the distribution of characteristics follow the data provided by the Japanese Statistical Bureau.

Confirmatory factor analysis was conducted in advance to justify the reliability of the survey. The results were highly consistent with the original author's findings and the value of Cronbach's alpha also validates for three of four constructs. The Cronbach's alpha coefficients for traditional husband (TH), traditional wife (TW), wife's selfactualization (SA) and husband alterations (HA) constructs are 0.844 , $0.468,0.764$, and 0.720 respectively. Although the reliability of TW is lower than 0.7 , we retain the construct score to keep consistency with Scanzoni [12]. Results of the confirmatory factor analysis are shown in the Appendix 1. Accordingly, the SRO scores are obtained by averaging items for each construct.

Respondents' answers were transformed into categorical values. Perceptions of SRO dimensions: 0: approval, 1: neutral, 2: approval; sex: 0 : female, 1 : male and decision making stage: 1 : information search, 2: evaluation of alternatives, 3 : final decision.

The four dimensions of SRO have been measured for 500 female and male samples, their reliability has been tested and the four construct scores have been standardized. SRO scores higher than 1 are interpreted as "approval", lower than 1 as "disapproval" and "neutral" otherwise. Six models have been built with isolated SRO dimensions (Table 1).

Interconnections between decision making authority, decision stage, gender and the four dimensions of Sex Role Orientation (TW, SA, TH, HA) have been tested using three-way ANOVA (Table 2).

In all 6 cases, the main effect of sex on decision authority were significant $(\mathrm{p}<0.001)$, in support of hypothesis 2 . The main effects of SRO on authority were found to be significant only in case of the male 
Citation: Varga Z, Dahana WD, Katsumata S (2018) The Asymmetric Effect of Sex Role Orientation on Japanese Family Purchase Decision Making J Account Mark 7: 266. doi: 10.4172/2168-9601.1000266

Page 4 of 8

\begin{tabular}{|l|l|l|l|}
\hline Models & Traditional/Egalitarian & SRO dimensions & Samples \\
\hline Case 1 & Traditional 1 & TW/TH & TW score for female samples and TH for male samples \\
\hline Case 2 & Traditional 2 & TW & TW score for both female and male samples \\
\hline Case 3 & Traditional 3 & TH & TH score for both female and male samples \\
\hline Case 4 & Egalitarian 1 & SA/HA & SA score for female samples and HA for male samples \\
\hline Case 5 & Egalitarian 2 & SA & SA score for both female and male samples \\
\hline Case 6 & Egalitarian 3 & HA & HA score for both female and male samples \\
\hline
\end{tabular}

Table 1: SRO measures and research models.

\begin{tabular}{|c|c|c|c|c|c|c|c|c|c|c|c|}
\hline Case 1 & Df & $\begin{array}{l}\text { Sum } \\
\text { square }\end{array}$ & \begin{tabular}{|l} 
Mean \\
square
\end{tabular} & F value & $\operatorname{Pr}(>\mathrm{F})$ & Case 4 & Df & Sum square & Mean square & F value & $\operatorname{Pr}(>\mathrm{F})$ \\
\hline SRO (TW/TH) & 2 & 0.13 & 0.06 & 0.69 & 0.50 & SRO (SA/HA) & 2 & 0.04 & 0.02 & 0.23 & 0.80 \\
\hline Sex & 1 & 39.43 & 39.43 & 436.89 & $0.00^{* * *}$ & Sex & 1 & 39.58 & 39.58 & 439.42 & $0.00^{* * *}$ \\
\hline DS & 2 & 0.06 & 0.03 & 0.35 & 0.71 & DS & 2 & 0.06 & 0.03 & 0.35 & 0.70 \\
\hline SRO $\times$ Sex & 2 & 0.72 & 0.36 & 3.96 & $0.02^{*}$ & SRO $\times$ Sex & 2 & 0.89 & 0.45 & 4.96 & $0.01^{*}$ \\
\hline SRO $\times$ DS & 4 & 0.06 & 0.01 & 0.17 & 0.96 & $S R O \times D S$ & 4 & 0.06 & 0.01 & 0.15 & 0.96 \\
\hline Sex $\times$ DS & 2 & 0.16 & 0.08 & 0.90 & 0.41 & Sex $\times$ DS & 2 & 0.15 & 0.08 & 0.84 & 0.43 \\
\hline SRO $\times$ Sex $\times$ DS & 4 & 0.02 & 0.01 & 0.07 & 0.99 & SRO $\times$ Sex $\times$ DS & 4 & 0.07 & 0.02 & 0.20 & 0.94 \\
\hline Residuals & 1482 & 133.77 & 0.09 & & & Residuals & 1482 & 133.49 & 0.09 & & \\
\hline Case 2 & Df & $\begin{array}{l}\text { Sum } \\
\text { square }\end{array}$ & \begin{tabular}{|l|} 
Mean \\
square
\end{tabular} & F value & $\operatorname{Pr}(>\mathrm{F})$ & Case 5 & Df & Sum square & Mean square & F value & $\operatorname{Pr}(>\mathrm{F})$ \\
\hline SRO (TW) & 2 & 0.05 & 0.03 & 0.29 & 0.75 & SRO (SA) & 2 & 0.18 & 0.09 & 1.03 & 0.36 \\
\hline Sex & 1 & 39.20 & 39.20 & 435.46 & $0.00^{* * *}$ & Sex & 1 & 39.13 & 39.13 & 434.98 & $0.00^{* * *}$ \\
\hline DS & 2 & 0.06 & 0.03 & 0.35 & 0.70 & DS & 2 & 0.06 & 0.03 & 0.35 & 0.70 \\
\hline SRO $\times$ Sex & 2 & 1.35 & 0.67 & 7.48 & $0.00^{* * *}$ & SRO $\times$ Sex & 2 & 1.35 & 0.67 & 7.48 & $0.00^{* * *}$ \\
\hline SRO $\times$ DS & 4 & 0.06 & 0.02 & 0.17 & 0.95 & SRO $\times$ DS & 4 & 0.03 & 0.01 & 0.10 & 0.98 \\
\hline Sex $\times$ DS & 2 & 0.15 & 0.07 & 0.83 & 0.44 & Sex $\times$ DS & 2 & 0.15 & 0.07 & 0.81 & 0.44 \\
\hline SRO $\times$ Sex $\times$ DS & 4 & 0.06 & 0.01 & 0.17 & 0.96 & SRO $\times$ Sex $\times$ DS & 4 & 0.15 & 0.04 & 0.40 & 0.81 \\
\hline Residuals & 1482 & 133.42 & 0.09 & & & Residuals & 1482 & 133.31 & 0.09 & & \\
\hline Case 3 & Df & $\begin{array}{l}\text { Sum } \\
\text { square }\end{array}$ & $\begin{array}{l}\text { Mean } \\
\text { square }\end{array}$ & F value & $\operatorname{Pr}(>\mathrm{F})$ & Case 6 & Df & Sum square & Mean square & F value & $\operatorname{Pr}(>\mathrm{F})$ \\
\hline SRO (TH) & 2 & 1.55 & 0.78 & 8.67 & $0.00^{* * *}$ & SRO (HA) & 2 & 3.98 & 1.99 & 22.06 & $0.00^{* * *}$ \\
\hline Sex & 1 & 38.36 & 38.36 & 428.86 & $0.00^{* * *}$ & Sex & 1 & 36.01 & 36.01 & 398.85 & $0.00^{* * *}$ \\
\hline DS & 2 & 0.06 & 0.03 & 0.35 & 0.70 & DS & 2 & 0.06 & 0.03 & 0.35 & 0.71 \\
\hline SRO $\times$ Sex & 2 & 1.61 & 0.80 & 8.98 & $0.00^{* *}$ & SRO $\times$ Sex & 2 & 0.25 & 0.13 & 1.40 & 0.25 \\
\hline SRO $\times$ DS & 4 & 0.06 & 0.02 & 0.17 & 0.95 & $S R O \times D S$ & 4 & 0.05 & 0.01 & 0.14 & 0.97 \\
\hline Sex $\times$ DS & 2 & 0.15 & 0.08 & 0.85 & 0.43 & Sex $\times$ DS & 2 & 0.14 & 0.07 & 0.78 & 0.46 \\
\hline SRO $\times$ Sex $\times$ DS & 4 & 0.02 & 0.00 & 0.05 & 1.00 & SRO $\times$ Sex $\times$ DS & 4 & 0.03 & 0.01 & 0.09 & 0.98 \\
\hline Residuals & 1482 & 132.54 & 0.09 & & & Residuals & 1482 & 133.82 & 0.09 & & \\
\hline
\end{tabular}

DS: Decision Stage; ${ }^{*} p<0.05,{ }^{* *} p<0.01,{ }^{* *} p<0.001$.

Table 2: Results of three-way ANOVA

\begin{tabular}{|c|c|c|c|}
\hline Hypotheses & Dependent variable1 & Independent variable & Results \\
\hline Hypothesis 1 & Decision authority & SRO (TW, SA, TH, HA) & Partially supported (TH, HA) \\
\hline Hypothesis 2 & Decision authority & Sex & Supported \\
\hline Hypothesis 3 & Decision authority & Decision stage & Rejected \\
\hline Hypothesis 4 & Decision authority & SRO $\times$ Sex & Partially supported (TW, SA) \\
\hline Hypothesis 5 & Decision authority & SRO $\times$ Decision stage & Rejected \\
\hline Hypothesis 6 & Decision authority & SRO $\times$ Sex $\times$ Decision stage & Rejected \\
\hline
\end{tabular}

Table 3: Summary of hypothesis testing results.

dimensions (TH, HA), partially supporting hypothesis 1. Further, the moderating effects of sex were prominent in the case female dimensions (TW, SA), providing partial supports for hypothesis 4 . The results also revealed that the main effects of decision stage, along with its moderating effects, on authority appear to be insignificant for any of the three stages, leading to the rejection of hypothesis 3,5 , and 6 . Table 3 summarizes the hypotheses testing results.
The effect of SRO on decision making authority for husbands and wives was arranged in an asymmetric way (Figure 2). In case of traditional dimensions (TW, TH), an increase in SRO leads to segregation from joint decision making. On the other hand, in case of higher scores in egalitarian dimensions (SA, HA), the lines tend to converge toward syncretic decision making. 
Citation: Varga Z, Dahana WD, Katsumata S (2018) The Asymmetric Effect of Sex Role Orientation on Japanese Family Purchase Decision Making J Account Mark 7: 266. doi: 10.4172/2168-9601.1000266

\section{Case $1(\mathrm{TW} / \mathrm{TH})$}

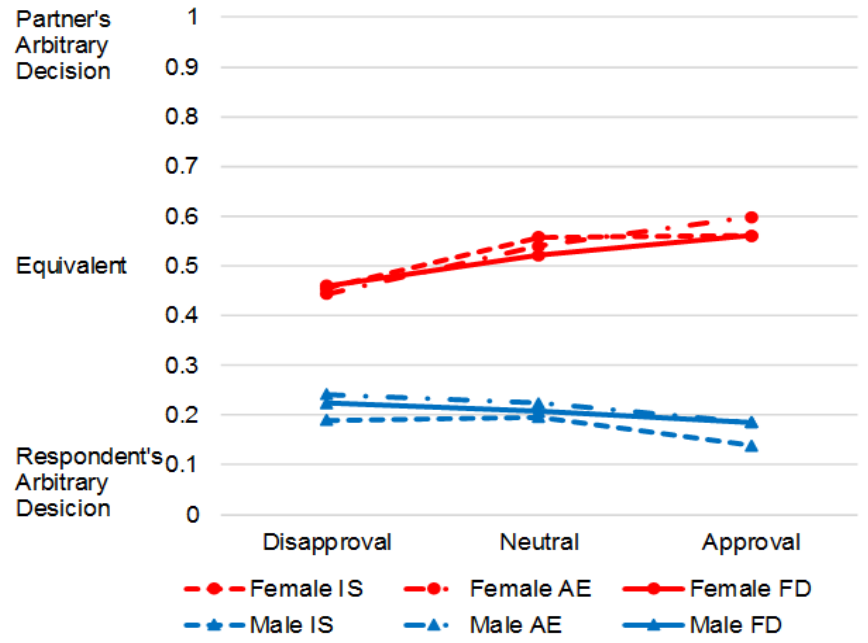

Case 2 (TW)

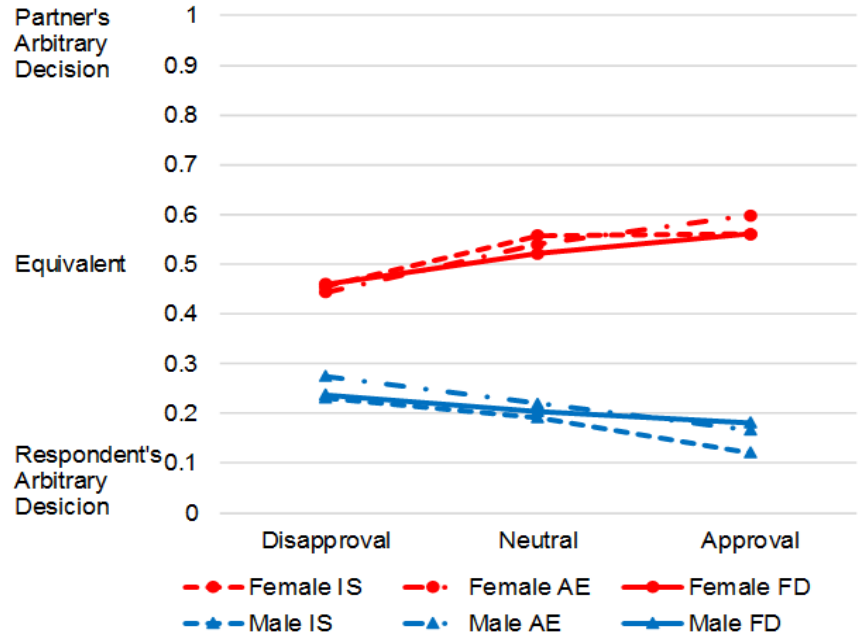

Case $3(T H)$

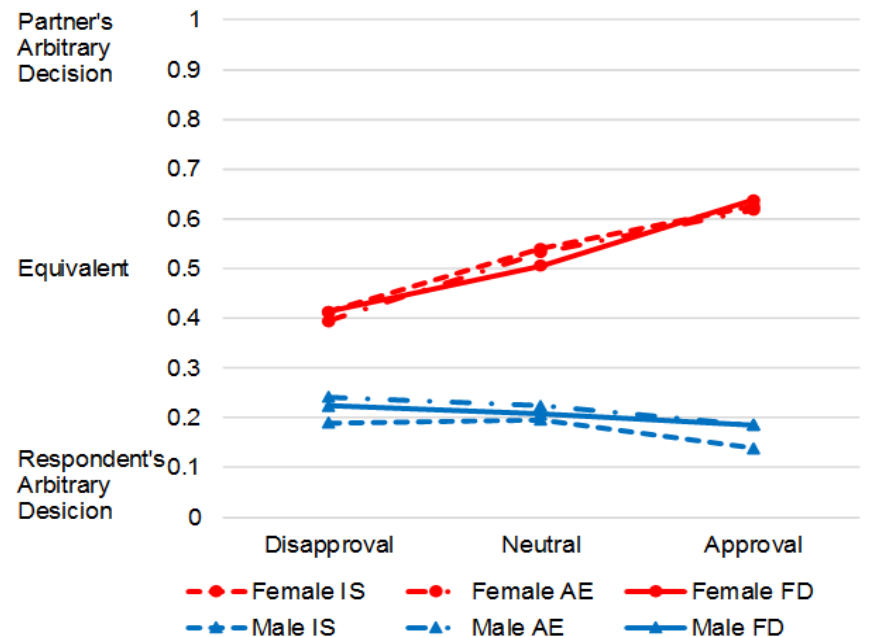

Case 4 (SA/HA)

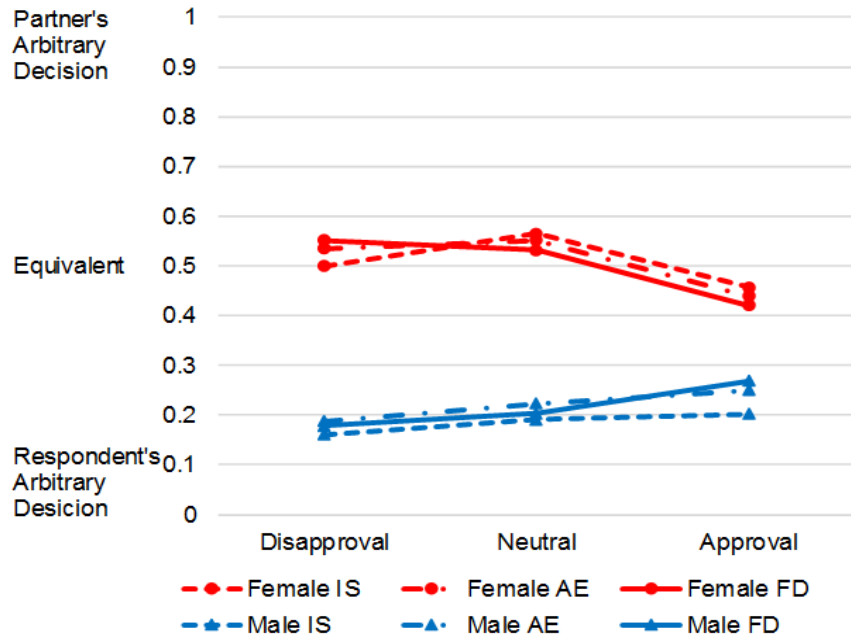

Case 5 (SA)

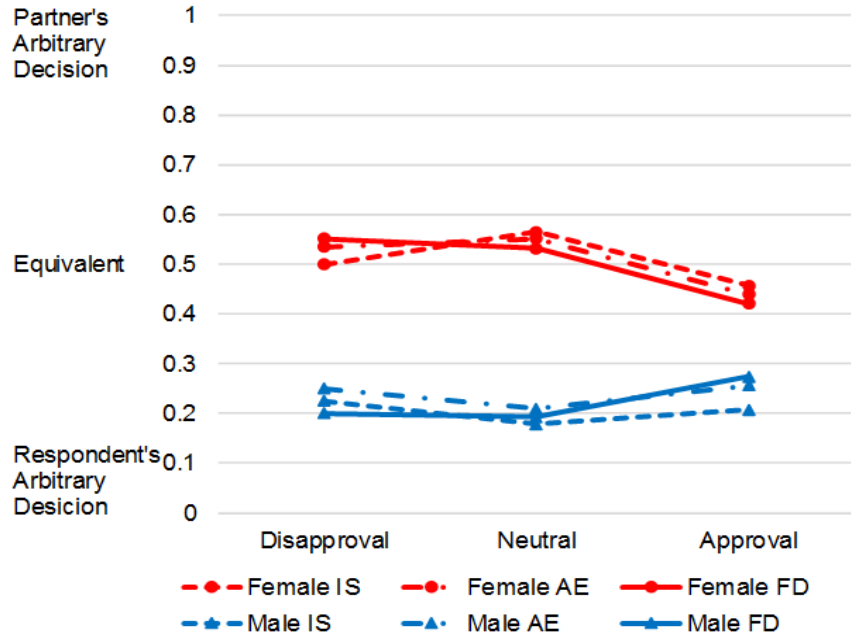

Case $6(\mathrm{HA})$

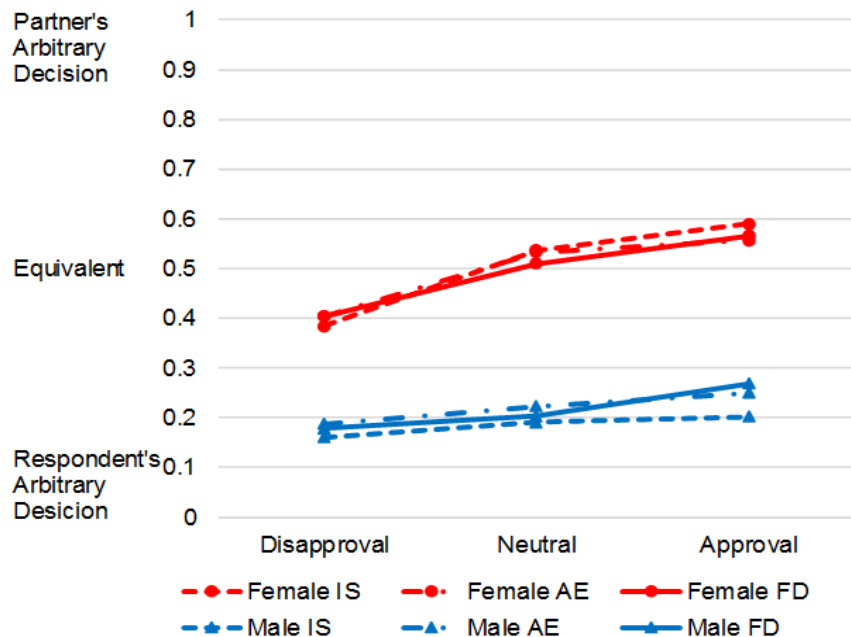

Figure 2: SRO's effect on authority for husbands in each decision stage. 


\section{Discussion and Implications}

\section{SRO's effect on authority}

This study confirmed the SRO's effect on family decision making authority. However, the effect is not as direct as it has been presumed in the previous studies. In particular, the husband's SRO dimensions (TH, HA) significantly affect decision making authority of households who consider buying a new car. That is, higher traditional husband role perception leads to greater weight of husbands' authority in engaging various buying tasks, as perceived by the respondents. On the other hand, the wife's dimensions (TW and SA) did not seem to cause authority differences between husband and wife. Accordingly, a clear asymmetric effect have been revealed between female and male dimensions; while the husband's SRO is the main predictor in determining decision authority during family decisions, the wives' SRO dimensions appear to be significant only when the effects are seen as conditional on gender. Despite several authors pronounce that family decision making has been changing dramatically towards egalitarian decision making [53], in case of Japanese society, automobile purchases still heavily rely on husband dominated decisions. The results support the findings of Ford et al. [13] about Japanese male dominance, and indicate little or no change within the past 23 years.

\section{SRO's inverse effect on the husband and the wife}

The effect of gender on decision authority was found to be strong and significant. The study echoed previous studies by providing largescale empirical validation that consumer purchase decisions of durable goods are governed largely by husband dominated decision making. However, Western studies' indication of women's increasing influence seems not to be apparent in Japan. Men's prevailing dominance in contrast with Western egalitarianism might be attributable to the substantial cultural differences [11] and the embryotic phase of gender equality movements in Japan.

\section{Authority across decision stages}

In contrast with previous findings that authority levels vary across decision stages and become exceptionally perceptible at the final decision stage [1,54-56], our study found no significant relationship between decision stages and authority. Davis and Rigaux [17] stated that in case of automobile purchases, wives are more dominant during the problem recognition phase and husbands exert higher authority during information search and at the final decision. In contrast with the expectations, our research demonstrated that in Japanese families, authority levels remain stable during the entire decision making process and the extent of household's reliance on the husband's authority versus adopting syncretic decisions are similar from problem recognition stage to the final decision stage. The contradiction with previous findings might be explained by the presence of intense cultural differences [11] and the highly gender-specialized perception of product category by Japanese society.

\section{Gender as a moderating factor between SRO and authority}

In most cases (4 out of 6), strong and statistically significant relationship was observed between gender, SRO and authority, particularly high for the wives' dimensions (TW and SA). SRO's significant effect on women's perception of authority indicates that gender stereotype perceptions do affect men and women in different ways. The findings reveal that modern wives are more likely to interfere with the traditional husband dominated decision-making in a desire for collaborative, syncretic decisions. On the other hand, even husbands with modern SRO perceptions show little willingness to share their decision making authority to their wives. This behavioral pattern remains stable across all stages.

\section{Research implications}

The findings provide a basis for a broader range of future implications. The work should be viewed as a milestone in understanding the effect of Sex Role Orientation on household consumer behavior by providing evidence that measuring overall SRO of a couple could lead to imprecise interpretation because SRO affects husbands and wives in an asymmetrical way. We propose that in order to understand the intricacies of family behavior in a more comprehensive manner, female and male dimensions should be both measured separately for each individual.

Besides setting a direction for avant-garde research, previous findings might be reexamined in a deeper level by dissecting the elements of SRO and measuring their individual relationships with some variables of interest. Given the interdisciplinary nature of the field, we anticipate that the process should be replicated for a large number of cases.

Cross-cultural comparison may provide deeper insight into the intricacies of household behavior in more general contexts. The theory that applies to Western households seems to partially hold on Japanese families, however, an analogy with other countries should elicit more fruitful findings for academic as well as practitioners.

\section{Managerial implications}

As the single greatest engine of economic growth in the world, automotive industry constitutes $15 \%$ of Japanese export. Automobile purchase decision making has been the subject of a large number of previous studies due to the fact that car purchases represent a considerable part of consumer durable decision making $[1,17,57]$. Japanese market is considered to be difficult to enter and Western automobile manufacturer's lack of success might be an evidence for the obstacles in understanding the Japanese culture's puzzle of complexity. For global marketers, understanding the local market characteristics is critical from managerial point of view. A failure to understand the characteristics of consumers in local market might cause frictions and reduce marketing effectiveness; thus, any strategy aimed to tap a local market should be well adapted to the local culture based on better understanding of decision making patterns of the consumers making up the market [57]

Further, the findings suggest that in Japanese durable markets, the effectiveness of marketing efforts could be improved by strategically targeting the efforts toward male consumers. Although this might be intuitive for a number of practitioners, the fact remains that this research is the first to document these effects empirically.

Finally, considering the slowly converging Japanese lifestyle towards Western norms [11] and the gradual transition of family values, it would be critical to account for potential behavioral changes of families when predicting family decision process of Japanese households in the future. Additionally, more comprehensive investigation of gender equality's adoption in different cultures would enable richer interpretation regarding Japanese household behavior. We leave these as future research issues.

\section{Acknowledgment}

This research was supported by Japan Society for the Promotion of Science KAKENHI [grant number A26285095a]. 
Citation: Varga Z, Dahana WD, Katsumata S (2018) The Asymmetric Effect of Sex Role Orientation on Japanese Family Purchase Decision Making J Account Mark 7: 266. doi: 10.4172/2168-9601.1000266

\section{References}

1. Belch MA, Willis LA (2002) Family decision at the turn of the century: Has the changing structure of households impacted the family decision-making process? J Consumer Res 2: 111-124.

2. Buss WC, Schaninger CM (1983) The influence of sex roles on family decision processes and outcomes. ACR North American Advances.

3. Buss WC, Schaninger CM (1987) An overview of dyadic family behavior and sex roles research: A summary of findings and an agenda for future research. Review of Marketing, pp: 293-324.

4. Qualls WJ (1987) Household decision behavior: The impact of husbands' and wives' sex role orientation. J Consumer Res 14: 264-279.

5. Qualls WJ, Jaffe F (1992) Measuring conflict in household decision behavior: Read my lips and read my mind. ACR North American Advances.

6. Chia RC, Moore JL, Lam KN, Chuang CJ, Cheng BS (1994) Cultural differences in gender role attitudes between Chinese and American students. Sex Roles 31: 23-30.

7. Lara-Cantu MA, Navarro-Arias R (1987) Self-descriptions of Mexican college students in response to the Bem Sex Role Inventory and other sex role items. J Cross-Cult Psychol 18: 331-344.

8. Novakovic T, Kidd AH (1988) Gender self-concepts in the USA and Yugoslavia. Psychol Rep 62: 611-617.

9. Ward C, Sethi RR (1986) Cross-cultural validation of the Bem Sex Role Inventory: Malaysian and South Indian research. J Cross-Cult Psychol 17: 300 314.

10. Williams JE, Satterwhite RC, Best DL (1999) Pancultural gender stereotypes revisited: The five factor model. Sex Roles 40: 513-525.

11. Sugihara Y, Katsurada E (2002) Gender role development in Japanese culture: Diminishing gender role differences in a contemporary society. Sex Roles 47 443-452.

12. Scanzoni J (1975) Sex roles, economic factors, and marital solidarity in black and white marriages. jJ Marriage Fam 37: 130-144.

13. Ford JB, LaTour MS, Henthorne TL (1995) Perception of marital roles in purchase decision processes: a cross-cultural study. J Acad Mark Sci 23: 120-131.

14. Strodtbeck FL (1951) Husband-wife interaction over revealed differences. Am Sociol Rev 16: 468-473.

15. Blood RO Jr, Wolfe DM (1960) Husbands and wives: The dynamics of married living. Free Press, Glencoe, IL.

16. Cunningham IC, Green RT (1974) Purchasing roles in the US family, 1955 and 1973. 円 Mark 38: 61-64.

17. Davis HL, Rigaux BP (1974) Perception of marital roles in decision processes. j Consumer Res 1: 51-62.

18. Ferber R, Lee LC (1974) Husband-wife influence in family purchasing behavior. 户 Consumer Res 1: 43-50.

19. French JR, Raven B, Cartwright D (1959) The bases of social power. Classics of Organization Theory 7: 311-320.

20. Davis HL (1976) Decision making within the household. J Consum 2: 241-260

21. Bonfield EH (1978) Perception of marital roles in decision processes: Replication and extension. Adv Consum Res 5: 300-307

22. Putman M, Davidson WR (1987) Family Purchasing Behavior: I Power and Influence-Family Roles. Management Horizons.

23. Lazer W, Smallwood JE (1977) The changing demographics of women. ऐ Mark 41: 14-22.

24. Weinberg CB, Winer RS (1983) Working wives and major family expenditures: Replication and extension. J Consumer Res 10: 259-263.

25. Spiro RL (1983) Persuasion in family decision-making. J Consumer Res 9 393-402.

26. Kenkel WF (1961) Family interaction in decision-making on spending Household Decision Making: Consumer Behavior, pp: 140-164.
27. Hallenbeck PN (1966) An analysis of power dynamics in marriage. J Marriage Fam 28: 200-203.

28. Broderick C, Smith J (1979) General systems approach to the family.

29. Rogler LH, Procidano ME (1986) The effect of social networks on marital roles: A test of the Bott hypothesis in an intergenerational context. J Marriage Fam 48: 693-701.

30. Spanier GB, Lewis RA (1980) Marital quality: A review of the seventies. J Marriage Fam 42: 825-839.

31. Raven BH, Centers R, Rodrigues A (1975) The bases of conjugal power Power in Families, pp: 217-232.

32. Sullivan GL, O'Connor PJ (1988) The family purchase decision process: A cross-cultural review and framework for research. Southwest Journal of Business and Economics 6: 43 .

33. Roberts ML, Wortzel LH (Eds.) (1984) Marketing to the changing household: Management and research perspectives. Ballinger Publishing Company.

34. Scanzoni JH, Szinovacz ME (1980) Family decision-making: a developmenta sex role model. Beverly Hills, California, Sage Publications.

35. Scanzoni L, Scanzoni J (1976) Men, women and change: A sociology of marriage and family. Beverly Hills, California, Sage Publications.

36. Rodman H (1972) Marital power and the theory of resources in cultural context. J Comp Fam Stud 3: 50-69.

37. Schaninger CM, Buss WC, Grover R (1982) The effect of sex roles on family finance handling and decision influence. An Assessment of Marketing Thought and Practice, pp: 43-46.

38. Schaninger CM, Buss WC (1985) The relationship of sex-role norms to household task allocation. Psychology and Marketing 2: 93-104.

39. Osmond MW, Martin PY (1975) Sex and sexism: A comparison of male and female sex-role attitudes. J Marriage Fam 37: 744-758.

40. Harcar T, Spillan JE (2006) Exploring Latin American family decision-making using correspondence analysis. Journal of World Business 41: 221-232.

41. Onkvisit S, Shaw JJ (1994) Consumer behavior: Strategy and analysis Macmillan college publishing company.

42. Reischauer E, Craig EA (1973) Tradition and transformation. Bostons Houghton Mifflin Co.

43. Hofstede G (2003) Culture's consequences: Comparing values, behaviors institutions and organizations across nations. Sage Publications.

44. Brislin R (1993) Understanding culture's influence on behavior. Harcourt Brace Jovanovich.

45. Whitaker A, Johnson J, Shaffer D, Rapoport JL, Kalikow K, et al. (1990) Uncommon troubles in young people: Prevalence estimates of selected psychiatric disorders in a non-referred adolescent population. Arch Gen Psychiatry 47: 487-496.

46. Ellwood DT (1993) The changing structure of American families the bigge family planning issue. Journal of the American Planning Association 59: 3-8.

47. Jacques JM (1998) Changing marital and family patterns: A test of the postmodern perspective. Sociological Perspectives 41: 381-413.

48. Rosen DL, Granbois DH (1983) Determinants of role structure in family financia management. J Consumer Res 10: 253-258.

49. Kamo Y (1988) Determinants of household division of labor: Resources, power and ideology. J Fam Issues 9: 177-200.

50. Wilkes RE (1975) Husband-wife influence in purchase decisions: a confirmation and extension. J Mark Res 12: 224-227.

51. Belch G, Belch M, Ceresino G (1985) Parental and teenage influences in family decision making. J Bus Res 13: 163-176.

52. Hempel DJ (1975) Family role structure and housing decisions. Adv Consum Res 2: 71-80.

53. Felmlee DH (1994).Who's on top? Power in romantic relationships. Sex Roles 31: 275-295.

54. Beatty SE, Talpade, S (1994) Adolescent influence in family decision making: a replication with extension. J Consumer Res 21: 332-341. 
Citation: Varga Z, Dahana WD, Katsumata S (2018) The Asymmetric Effect of Sex Role Orientation on Japanese Family Purchase Decision Making. J Account Mark 7: 266. doi: 10.4172/2168-9601.1000266

Page 8 of 8

55. Davis HL (1971) Measurement of husband-wife influence in consumer purchase decisions. J Mark Res 8: 305-312.

56. Wut TM, Chou TJ (2013) Do family members agree on family purchase decision? An empirical study among families in Hong Kong. Int J Consum Stud 37: 344-350.

57. Usunier JC, Lee JA, Lee J (2005) Marketing across cultures. Pearson Education. 